\title{
Isolation and Identification of Fungi Associated with Habanero Pepper (Capsicum chinense jacq) Using Basic Molecular Techniques
}

\section{"IKECHI-NWOGU, GC; ODOGWU, AB; UKOMADU, J; USIAKPONEBRO, EP}

Department of Plant Science and Biotechnology, Faculty of Science, University of Port Harcourt. Choba, P. M. B. 5323, Port Harcourt, Nigeria

\author{
* Corresponding Author Email: chinyerum.ikechi-nwogu@ uniport.edu.ng, Tel: +2348032325098, +2347039338412 \\ Other authors Email blessing.odogwu@uniport.edu.ng, Tel.: +2348036772711, josephine.ukomadu@uniport.edu.ng, Tel.: \\ +2348147651600,ebrus_luv@yahoo.com,Tel.: +2347052744632
}

\begin{abstract}
Habanero pepper (Capsicum chinense Jacq.) is an economically important vegetable. It is used as spices for foods and for medicinal purposes in many parts of the country. Despite the importance of the crop, it has been observed that during storage, the fruits of the Habanero pepper (HP) shelf-life is reduced by several post-harvest diseases caused by fungal pathogens. A study was conducted to identify the common fungal pathogens causing post-harvest rot of Habanero fruits at the daily market in Omoko Aluu Town, Rivers State. The DNA of the most common fungal isolate HP-02 was molecularly characterized using Internal Transcribed Spacer 1 (ITS-1) molecular marker. The HP-02 isolate DNA sequence was aligned using the Basic Local Alignment Search Tool for nucleotide (BLASTN) 2.8.0 version of the National Center for Biotechnology Information (NCBI) database. The results indicated that the HP-02 isolate sequence was $79 \%$ identical to Mucor irregularis and also Rhizomиcor viriabilis isolate SAPB3. These findings showed that Mucor irregularis, which was formerly known as Rhizomucor variabilis is one of the emerging causal fungal pathogens of post-harvest Habanero pepper.
\end{abstract}

DOI: https://dx.doi.org/10.4314/jasem.v25i7.4

Copyright: Copyright $\odot 2021$ Ikechi-Nwogu et al. This is an open access article distributed under the Creative Commons Attribution License (CCL), which permits unrestricted use, distribution, and reproduction in any medium, provided the original work is properly cited.

Dates: Received: 10 May 2021; Revised: 28 June 2021; Accepted: 01 July 2021

Capsicum chinense Jacq. (Habanero pepper) is a hot variety of Chili pepper; it is a perennial flowering plant of the Solanaceae family. It is locally known as atarodo by the Yorubas, osendu by the Igbos and attaruhu by the Hausas of Nigeria. The fruits of $C$. chinense varies greatly in both color and shape, some appears red, yellow and orange are the most widespread matured colors, but very few also appear brown and purple (Chinense species, 2012). The fruits are about 1 to 2.5 inches long, 1 to 2 inches in diameter and they are ere either lantern- in shape, round or oblong (Pepper facts, 2018). This plant thrives well in hot weather conditions. Fruits mature at about 100 to 120 days after transplanting (Marie, 2017). The Habanero pepper can be properly dried using a dehydrator, or other methods before preservation. It is of great economic importance, its use on food, ornamental products, pharmaceutical, and cosmetics (Dias et al., 2013, de Oliveira, et al., 2017). However, Pepper is faced with fungi diseases such as: Anthracnose, Cercospora leaf spot, damping off, Fusarium wilt, gray mold, Phytophtora blight, powdery mildew, southern blight, Verticullium wilt, white mold (Asare-Bediako et al., 2015). These fungi diseases are post-harvest disease that have caused 50\% loss in plants (Agrios, 2005). Given that there are different fungi species and the morphological identification is not adequate for taxonomy, more tools for fungi identification are needed. Identification and taxonomy of fungi pathogens are increasingly dependent on modern molecular techniques based on Polymerase Chain Reaction (PCR) amplification. Sequencing of the resulting PCR products has proven to be more reliable alternative to traditional methods of identification (Hariharan and Prasannath, 2021; Horton and Bruns, 2001). Many molecular classification approaches have been carried out for fungal organisms (Alsohaili, et al., 2018). In our world today, it is vital for fungi to be properly identified using molecular characterization. This study looks into the isolation and identification of fungi diseases associated with the Habanero pepper (Capsicum chinense).

\section{METHODS AND METHODS}

Study Area: The study was conducted in Mycology/Pathology laboratory of Plant Science and Biotechnology and Regional Centre for Biotechnology and Bio-fuel Research Laboratory where DNA extraction was carried out, University of Port Harcourt. Amplification and sequencing of the PCR products were done at the Habanero pepper with

* Corresponding Author Email: chinyerum.ikechi-nwogu@uniport.edu.ng, Tel: +2348032325098, 
disease symptoms were purchased Omoko Aluu Town, Port Harcourt, Rivers State, Nigeria International Institute for Tropical Agriculture (IITA) Ibadan both in Nigeria.

Isolation of Fungi from Capsicum chinense Jacq. Using Blotter Method: According to the rules of the international seed health testing association (ISTA, 2016), a standard blotter method was used to isolate fungi pathogens associated with Habanero pepper. The filter paper, distilled water (placed in a conical flask) and Petri dishes (wrapped in a foil paper) used for the work were first autoclaved at $121^{\circ} \mathrm{C}$ for $15 \mathrm{mins}$. The
Petri-dishes were lined with 3 layers of sterilized $9 \mathrm{~cm}$ Whatman's filter paper, the filter paper was soaked with little water and then the petri dishes were covered immediately. The pepper was surface sterilized in a beaker using $70 \%$ ethanol for 2-3minutes, discard the ethanol and rinsed with sterile distilled water twice. 45 pepper fruits were plated per Petri-dish (Plate 1a), the plates were then wrapped with masking tape and then labelled. Plated pepper was incubated at $25+2^{\circ} \mathrm{C}$ in the laboratory for 7 days. Unidentified fungus (Plate 1b), was sub-cultured on Potato Dextrose Agar (PDA) medium under darkness at room temperature $(25+$ $\left.2^{\circ} \mathrm{C}\right)$.
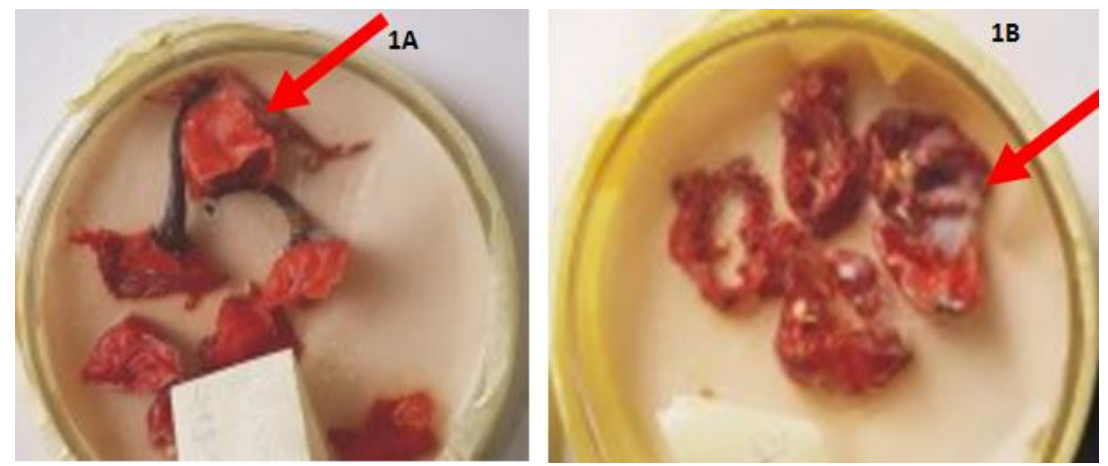

Plate 1A: Pepper on B lotter Paper and Plate 1B: Pepper on Blotter Paper after 7 Days (red arrow showing the fungus)

Preparation of Potato Dextrose Agar: To prepare potato infusion, $200 \mathrm{~g}$ of sliced, unpeeled potatoes was boiled in 1 liter of distilled water for 30 minutes. The boiled potato was then filtered through cheesecloth, saving effluent, which is potato infusion. The filtrate was transferred into measuring flask, $20 \mathrm{~g}$ of dextrose and $20 \mathrm{~g}$ of agar were added and the mixture was made up to 1litre with distilled water. The medium was shaken properly to mix well and then dispensed into $500 \mathrm{ml}$ flat bottom flasks. The flasks were plugged with cotton wool and foil and then autoclave at $121^{\circ} \mathrm{C}$ for 15 minutes. The medium was allowed to cool, then 3 drops of $25 \%$ lactic acid was added to each $500 \mathrm{ml}$ of medium and then it was stirred. About 10 to $20 \mathrm{ml} \mathrm{PDA}$ was dispensed into each sterile petri-dish and allowed to solidify (Ataga et al., 2010 and BAM, 2001). It was then shake to make sure it is very solid.

Inoculation of Fungal Organism: The inoculating loop was sterilized by dipping into $70 \%$ ethanol and then flaming in a Bunsen burner, waved a little to cool off, to prevent contamination. The sterile inoculating loop was used to pick up individual colonies that were isolated from the pepper seeds, and then transferred unto the sterilized Petri-dishes containing Potato Dextrose Agar medium. Each Petri-dish was sealed with masking tape, labelled with dates and placed upside down to prevent contamination from any moisture that may be present.
Incubation of Fungal Organism: The Petri dishes were incubated at room temperature $\left(25+2^{\circ} \mathrm{C}\right)$ for 7 days to obtain pure cultures of the fungal organism. A total of 5 Petri dishes were used for each fungus. The cultures were stored at $4^{\circ} \mathrm{C}$ prior to DNA extraction.

Extraction of Fungal DNA: The genomic DNA of pure cultures of Habanero pepper was extracted using protocol of Quick- DNA ${ }^{\mathrm{TM}}$ Fungal/Bacterial Miniprep Kit (Zymo Research Group, California, USA) as pronounced by the manufacturer, with modifications. DNA quantity and concentration were measured using the Nanodrop 2000c spectrophotometer (Thermo fisher Scientific Inc. Wilmington, Delaware, USA). The DNA purity was measured as a ratio of absorbance at $280 \mathrm{~nm}$ to that of $260 \mathrm{~nm}$. The quality of the gDNA HP-7A isolate was further quantified using the Agarose gel electrophoresis performed according to the modified method of Saghai-Maroof et al., (1984). The DNA sample HP-7A isolate was shipped for amplification and sequencing to the International Institute of Tropical Agriculture (IITA) Bioscience Center, Ibadan, Nigeria for. The primers used to amplify fragments of the nuclear ribosomal DNA (rDNA) of the HP-7A isolate were the Internal Transcribed Spacer 4 (ITS4) with the sequence TCCTCCGCTTATTGACATGS and ITS5 with the sequence GGAACTAAAAGTCGTAACAAGG. The 
amplicons were sequenced using the capillary electrophoresis sequencer. The DNA sequence file was saved in the Bioedit file with and extension. ab1. The sequence was analyzed using the Molecular Evolutionary Genetics Analysis (MEGA) version
7.0.26 software, and aligned using the Basic Local Alignment Search Tool for nucleotide (BLASTN) of the National Center for Biotechnology Information (NCBI) database.
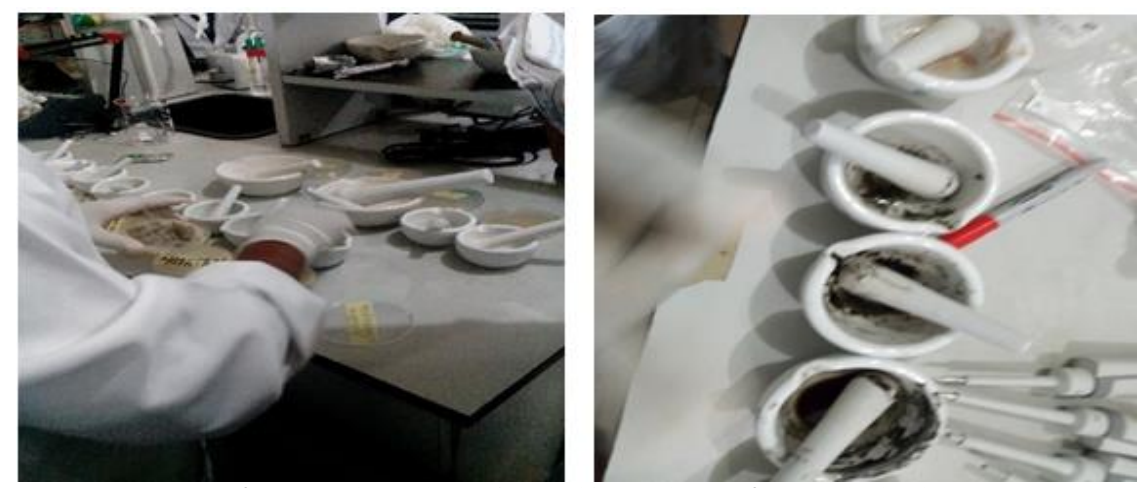

Plate 2a: Preparing cultures for crushing and Plate 2b: Crushed cultures

\section{RESULTS AND DISCUSSION}

Isolation of Fungi Associated with Capsicum chinense Jacq: The result of the fungal isolation is presented in plate 3.1. one unidentified fungal organisms HP- 02 was isolated and found to be associated with Habanero pepper (Capsicum chinense Jacq.) (Plate 2).

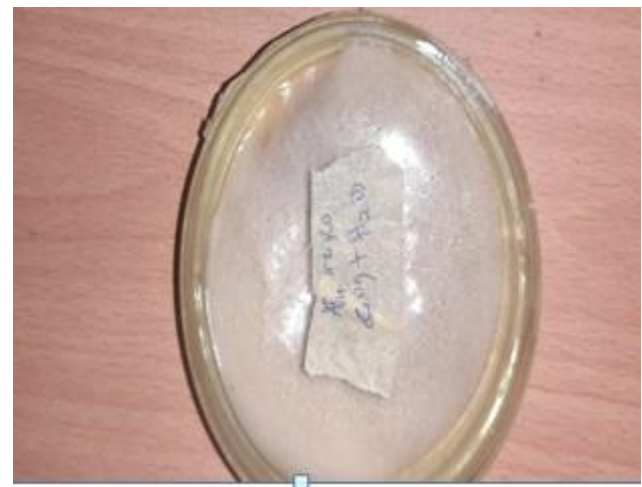

Plate 3: Pure Culture of Fungus Isolated from Pepper on Potatoes Dextrose Agar

DNA Extraction and Concentration Determination: The genomic DNA of the isolate HP-02 of Habanero pepper (Capsicum chinense Jacq.) was successfully extracted and showed good quality. The Nanodrop result showed that the concentrations of the DNA of the isolates were 43.9ng/ul, 20.2ng/ul and 44.3ng/ul respectively. While the absorption peak of the $260 \mathrm{~nm} / 280 \mathrm{~nm}$ readings were $1.59,1.81$ and 1.58 respectively and the $260 \mathrm{~nm} / 230 \mathrm{~nm}$ readings were $0.33,0.31$ and 0.33 respectively. However, to reduce the cost of sequencing, the isolate HP-02 with the highest DNA concentration was selected.

Polymerase Chain Reaction (PCR) and Gel
Electrophoresis: The result of the amplified DNA or PCR band of the isolate HP-02 is presented in Fig. 1. The amplified DNA showed bands on gel when observed under UV light. From the result, the ladder used indicated that the HP-02 isolate sequence had over 569 base pairs.

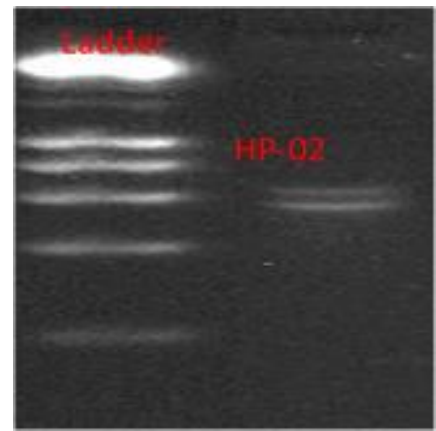

Fig 1: PCR products generated from Fungal DNA isolates

Sequence Alignment: The alignment results are presented in figure 2-3. Figure 3.4 displayed the alignment scores presented as purple lines. The scores of the alignments of all aligned sequences were below 200 .

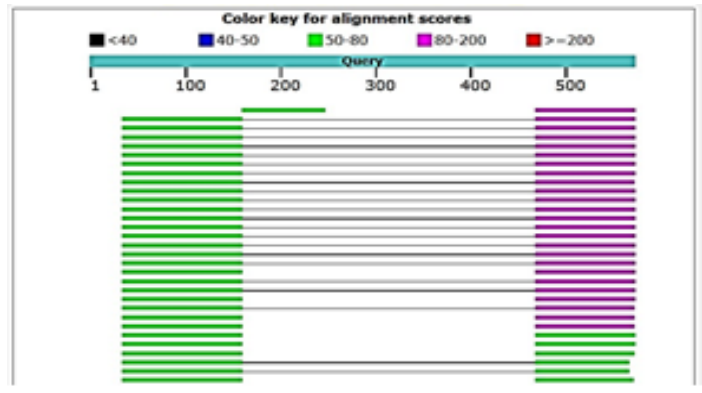

Fig 2: Alignment Scores of all Aligned Sequences 
Figures 3 indicated that the HP-02 isolate sequence was $79.09 \%$ identical to Mucor irregularis LHL1-2 (red arrow) and $79.09 \%$ identical to Rhizomucor variabilis SAPB3 (blue arrow). These findings showed that isolate HP-02 is a Mucor spp.

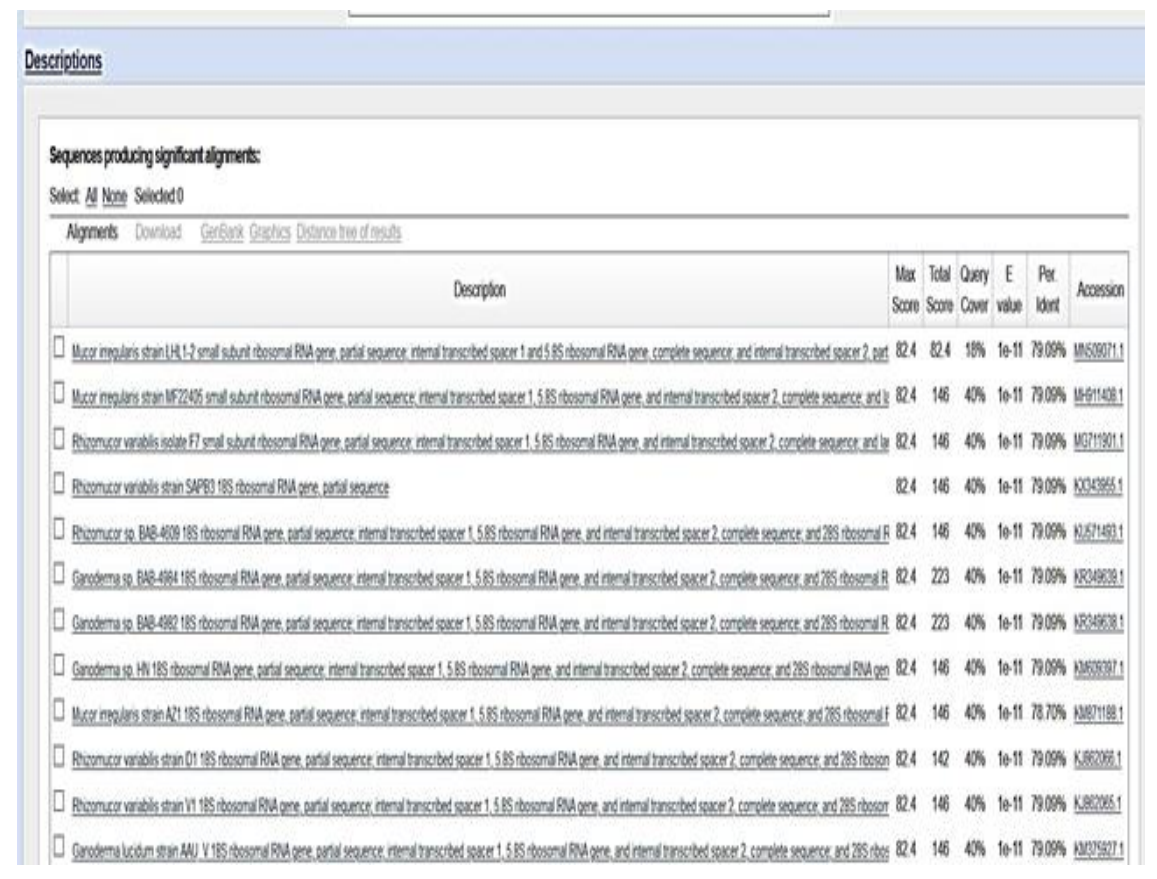

Fig 3: The Sequence Alignments of HP-02 isolate sequence with NCBI database sequences

Several organisms have been associated with the postharvest fruits of the Habanero pepper. Among the casual pathogens, lasiodiplodia, Aspergillus flavus, Penicilliim corylophilum, Asperillus fumigates, Aspergillus niger, Rhizopus stolonifer and Verticilliim spp. have all caused various diseases such as, damping off, wilting, powdery-mildew, soft rot and general spoilage in pepper and other plant species (Lema et al., 2018). In this study, Mucor irregularis was identified as a seed-borne pathogen associated with Habanero pepper. From the DNA alignment results, it was also noticed that the HP-02 isolate sequence was $79 \%$ identical to the partial sequence of the small subunit of ribosomal RNA gene of Rhizomucor variabililis isolate SAPB3 and this may be as a result of the ITS region sequenced. From PCR and gel electrophoresis result it was found that an organism of the Rhizomucor spp. was noticed to have mixed and was mimicking the Mucor irregularis spp. Mucor irregularis is an emerging fungal pathogen that can cause cutaneous infection and could cause death. However, little is known about its mechanism of pathogenesis, but for the purpose of this study, it brought to light that it can affect the fruit of pepper, thus damaging it. Mucor irregularis is a Mucor spp. belonging to the family Mucoraceae. It belongs to the fungi causing the group of infections referred to as zygomycosis. Zygomycosis infections includes, rhinocerebral infections as well as septic arthritis, dialysis associated peritoritis, renal and pulmonary infections. This moiocrobe is highly relevant to the safety and care plans of modern human population. (Doctor Fungus, 2019)

Conclusion: This study revealed that Mucor irregularis is one of the causal fungal pathogens of post-harvest rot of Habanero pepper. Sequence alignment result from the NCBI database showed that the HP-02 isolate sequence was $79.09 \%$ identical to Mucor irregularis LHL1-2. This research therefore paves way for further research using molecular tools in the identification of pathogenic organisms associated with diverse crops.

\section{REFERENCES}

Agrios, GN (2005). Plant Pathology. Fifth (5th) Edition. pp. 27-557

Alsohaili, SA; Bayan, MB (2018). Morphological and Molecular Identification of Fungi Isolated from Different Environmental Sources in the Northern Eastern Desert of Jordan. Jordan Journal of Biological Sciences. 11:329-337

Asare-Badiako, E; Addo-Quaye, A; Boakye, B; Sarbah, JM, Asante, P; Dorm, E (2015). Incidence and Severity of Viral and Fungi Diseases of Chili 
Pepper (Capsicum frutencens) in Some District in Ghana. International Journal of Plant and Soil Science. 7(3):147-159

Ataga, AE; Elenwo, EN; Nwachukwu, EO (2010). Laboratory Exercises and Series in Mycology. ACOTEC Technology, P.H., Nigeria. pp. 13-25, 97-183

Chinense Species". Capsicum Species. The Chili Man. Archived from the original on 23 February 2012/ Retrieved 8/06/2011

De Oliveira1, CVS; Matos, KS; De Albuquerquel, DMC; Hanada, RE; Da Silva, GF (2017) Identification of Colletotrichum isolates from Capsicum chinense in Amazon. Genetics and Molecular Research. 16 (2)

Dias, GB; Gomes, VM; Pereira, UZ (2013). Isolation, characterization and antifungal activity of proteinase inhibitors from Capsicum chinense Jacq. Seeds. Protein Journal.32: 15-26

Doctor Fungus (2019) "The Mucor Species" .http://drfungus.org/knowledge-base/ Retrieved 10/10/2019

Hariharan, G; Prasannath, K (2021). Recent Advances in Molecular Diagnostics of Fungal Plant Horton, TR; Burns TD (2001). The Molecular Revolution in Ectomycorrhizal Ecology: Peeking into the Black-Box. Molecular Ecology. 10:1855-1871.
ISTA (International Seed Testing Association) (2016). International Rules for Seed Testing. Rules Amendments. Seed Science Technology. 29: 1127.

Lema, AA; Mudansiru, a; Alenxander, BA; Sakinatu, MJ (2018). Evaluation of Fungal Species Isolated from Three Different Varieties of Pepper (Capsicum chinense, C. frutescens and C. annum L.) in Dutsin-ma, Katsina State. Annals of Biological Sciences. 6(1):13-17.

Marie, D (2017). Nutrition information. https://www.livestrong.com/article/349143-

habanero- pepper-nutrition-information/ Retrieved 10-09-2019. Pathogens. Mii Review: Frontiers in Cellular and Infection Microbiology. $1-14$

Pepper Facts (2018). http://www. ballintemple.com/ archive/organic/pepperfacts.html/Retrieved 09-92019.

Saghai-Maroof, M. A., Soliman, K. M, Jorgensen, R. A and Allard, R. W. (1984) Ribosomal DNA spacer-length polymorphism in barley: mendelian inheritance, chromosomal location and population dynamics. Proceedings of National Academy of Sciences of the United States of America. 81(24):801-8018. 